\title{
Reflexões sobre o Ação Humana de Mises*
}

\author{
Vernon L. Smith
}

\begin{abstract}
Resumo: O autor aplica a Economia Experimental para analisar algumas dos postulados de Mises em Ação Humana. Procura demonstrar, usando os postulados da Economia Experimental, que a ordem espontânea, operando por intermédio das instituições dos direitos de propriedade, exibe as características desejáveis que os austríacos reivindicaram. Este poder de demonstração é, para o autor, muito mais atraente do que o apelo à razão, especialmente enfatizado por Mises.

Palavras-Chave: Ação humana. Experimentos. Evolução da mente. Ações conscientes e inconscientes. Circuitos cerebrais. Nexo razão-emoção. Sociedade humana. Cooperação.
\end{abstract}

\section{Reflections on Mises' Human Action}

\begin{abstract}
The author applies the Experimental Economics to analyze some of the postulates of Mises in Human Action. He seeks to demonstrate, using the postulates of Experimental Economics, that the spontaneous order, operating through the institutions of property rights, displays the desirable characteristics that Austrians claimed. This power of demonstration is, to the author, much more attractive than the appeal to reason, especially emphasized by Mises.

Keywords: Human action. Experiments. Evolution of the mind. Conscious and unconscious actions. Brain circuits. Nexus reason-emotion. Human society. Cooperation.
\end{abstract}

Classificação JEL: B25, B31, B53, B59, D03

\footnotetext{
* O presente artigo é a versão escrita de uma conferência ministrada pelo autor em 1999 no Cato Institute em Washington, D.C., nos EUA. O texto foi publicado orginalmente em inglês da seguinte forma: SMITH, Vernon. Reflections on Human Action after 50 Years. In: Cato Journal, Vol. 19, No. 2 (Fall 1999), p. 195-214.

Traduzido do original em inglês para o português por Claudio A. Téllez-Zepeda.

** Vernon L. Smith é professor de Economia na Chapman University em Orange na Califórnia e pesquisador do Interdisciplinary Center for Economic Science da George Mason University (GMU) em Arlington na Virginia. Cursou a graduação em Artes Liberais na Friends University e em Engenharia Elétrica no California Institute of Technology (CalTech), o mestrado em Economia na Kansas University e o doutorado em Economia na Harvard University. Foi professor de Economia da Purdue University (1955-1967), da Stanford University (1961-1962), da Brown University (1967-1968), do Center for Advanced Study in the Behavioral Sciences (1972-1973), do CalTech (1973-1975), da University of Arizona (1976-2002) e da GMU (2003-2006). É autor de mais de duzentos artigos acadêmicos e dos livros Papers in Experimental Economics (Cambridge University Press, 1991), Bargaining and Market Behavior: Essays in Experimental Economics (Cambridge University Press, 2000) e Rationality in Economics (Cambridge University Press, 2009). Foi laureado com o Prêmio Nobel de Economia em 2002.

E-mail:vsmith@chapman.edu
} 
O núcleo do pensamento de Ludwig von Mises (1881-1973) é a teoria da ação humana, ou a praxeologia, a ciência geral que ele busca articular. Dentro desta ciência geral inclui-se - incutida nela - a cataláctica, ou a ciência das trocas ${ }^{1}$. Consequentemente, para Mises, tudo o que procuramos estudar em economia origina-se, em última análise, da escolha individual, para a qual a chave é a economia subjetivista, proveniente da revolução dos anos 1870 realizada por Carl Menger (1840-1921), William Stanley Jevons (1835-1882) e Léon Walras (1834-1910). Logo, "ao fazer sua escolha, o homem escolhe não apenas entre diversos bens materiais e serviços. Todos os valores humanos são oferecidos para opção. Todos os fins e todos os meios" [...] "são ordenados numa sequência e submetidos a uma decisão que escolhe um e rejeita outro" . Além disso, "a ação humana é necessariamente sempre racional"3. Para Mises, isto é uma verdade, e não uma hipótese a ser testada, passível de estar certa ou errada. Isso ocorre porque a praxeologia é neutra com respeito a quaisquer juízos de valor referentes a seus dados - ou seja, os fins últimos escolhidos na ação humana. Portanto, não existe uma base objetiva para afirmar que as escolhas de alguém possam ser irracionais.

Externalidades (sejam elas custos ou benefícios) não são problemas, a princípio, para Mises, porque viu claramente, assim como Ronald Coase (1910-2013), que elas envolvem a delimitação dos direitos de propriedade - o problema da propriedade de ninguém, ou os recursos de livre acesso público. Trata-se do problema de responsabilizar os indivíduos, ainda que a responsabilidade por esses custos

\footnotetext{
${ }^{1}$ Mises, Ludwig von. Human Action: A Treatise on Economics. San Francisco: Fox and Wilkes, $4^{\text {th }}$ rev. ed., 1996. p. 1-3. [N. do T.: Todas as citações da obra de Mises em inglês foram substituídas pela versão em português da seguinte edição brasileira: MISES, Ludwig von. Ação Humana: Um Tratado de Economia. Trad. Donald Stewart Jr. São Paulo: Instituto Ludwig von Mises Brasil, 3ª Ed., 2010. cit. p. 21-24].

${ }^{2}$ MISES. Ação Humana. p. 23.

${ }^{3}$ Idem. Ibidem., p. 43.
}

da ação humana sejam suportados por outros. Mises entende o princípio da responsabilidade como sendo amplamente aceito; ele atribui quaisquer deficiências alegadas a brechas "deixadas no sistema"4. Finalmente, nesta breve descrição, estão as bem conhecidas e vigorosas opiniões de Mises contra a intervenção:

Não há praticamente uma intervenção sequer do governo no mercado que, do ponto de vista dos cidadãos por ela afetados, não possa ser qualificada como um confisco ou como um donativo. [...] Não existe um método que se possa qualificar de justo e equitativo para exercer o tremendo poder que o intervencionismo coloca nas mãos do legislador e do governante ${ }^{5}$.

Vemos até mesmo o prenúncio do rent-seeking ${ }^{6}$ e da escolha pública quando Mises resume sua discussão sobre a corrupção como sendo inevitavelmente "uma consequência natural do intervencionismo"7. Portanto, a teoria da escolha é muito mais do que o lado "econômico" do empreendimento humano - ela é central a toda a ação humana.

Eu li o Ação Humana de Mises pela primeira vez em 1949, no ano em que o livro foi originalmente lançado, quando era um formando no CalTech, graduando-me em Engenharia Elétrica. Essa foi uma das muitas razões pelas quais eu subsequentemente migrei para a Economia. Relendo Mises depois de mais de cinquenta anos, estou impressionado com o quão estimulante, relevante e incisivo é o livro Ação Humana para o status da Ciência Econômica no início do terceiro milênio. A obra tem sobrevivido bem porque muitos de

\footnotetext{
${ }^{4}$ Idem. Ibidem., p. 749-50.
}

${ }^{5}$ Idem. Ibidem., p. 834.

6 No linguajar técnico econômico em português é costume manter o termo no original em inglês, no entanto, algumas vezes "rent-seeking" é traduzido como "busca de renda". O conceito é utilizado para descrever a tentativa de derivar renda econômica por intermédio da manipulação do ambiente social ou político no qual as atividades econômicas ocorrem, em vez de agregar valor. (N. do T.)

${ }^{7}$ MISES. Op. cit., p. 836. 
seus principais temas - direitos de propriedade, regras de responsabilidade, a eficácia dos mercados, a futilidade do intervencionismo, a primazia do indivíduo - têm se tornado elementos importantes na teoria e na política microeconômica. Além disso, esses temas têm se tornado importantes por causa de Mises, de F. A. Hayek (1899-1992), e outros fronteiriços à Escola Austríaca - como, por exemplo, o já citado Ronald Coase, bem como Armen Alchian (1914-2013), Douglass North, James M. Buchanan (1919-2013), Gordon Tullock, George Stigler (1911-1991) e William Vickrey (1914-1996), para nomear alguns -, e não devido à teoria econômica do mainstream. Há muito em Mises para ser atualizado por causa das coisas que pensamos que sabemos agora e que não sabíamos há mais de cinquenta anos. Contudo, a mensagem básica de Mises a respeito de como as economias funcionam é tão boa hoje como era na época em que $A c ̧ a \tilde{o}$ Humana foi lançado. O que sofreu grandes avanços são as metodologias para estudar a natureza do processo humano para a tomada de decisões. Neste breve ensaio, apanharei diversos temas de Mises que utilizarei para ilustrar esta mudança. Também complementarei esta discussão com alguns comentários sobre Hayek, dado que em 1999 comemorou-se, também, o centésimo aniversário de seu nascimento. Portanto, há muito o que celebrar com os economistas austríacos.

\section{I - Sobre a Ação Humana e EXPERIMENTOS EM LABORATÓRIO}

Os pontos de vista de Ludwig von Mises sobre os métodos experimentais refletem a perspectiva metodológica que era universal na profissão há mais de cinquenta anos - ou seja, a visão de que a Economia é necessariamente uma ciência não-experimental:

Existem [...] alguns naturalistas e físicos que censuram a Economia por não ser uma ciência natural e não aplicar os métodos e procedimentos de laboratório [...]. Mas a experiência à qual as ciências naturais de- vem todo seu sucesso é aquela em que os elementos específicos que sofrem alteração podem ser observados isoladamente [...]. A experiência com a qual as ciências da ação humana têm de lidar é sempre uma experiência de fenômenos complexos. No que diz respeito à ação humana, não se pode realizar experiência em laboratório. Nunca temos condição de observar a mudança em um elemento isolado, mantendo-se todos os demais inalterados ${ }^{8}$.

Meu ponto de vista é de que a razão pela qual se acreditava que a economia era uma ciência não-experimental era simplesmente o fato de que quase ninguém tinha se empenhado ou importado. A postura de Mises era, naquele tempo, então, universal, e ainda hoje é frequentemente encontrada. Dessa maneira, Charles A. Holt, um ilustre e destacado experimentalista da Virginia University, foi advertido pelo seu orientador de que a economia experimental "era uma perda de tempo nos anos 1960 e continuaria sendo uma perda de tempo na década de $1980 "$. O que não está claro é por que o que tinha sido uma perda de tempo na década de 1960 tinha conseguido sobreviver para continuar sendo novamente uma perda de tempo na década de 1980. Nos últimos meses de 1999, aguardo com expectativa para que ela seja considerada outra perda de tempo na década de 1990. Recordo-me da observação irônica de Paul Samuelson (1915-2009), de que a ciência avança de funeral em funeral.

De fato, no ano de 1998 tivemos o quinquagésimo aniversário (que passou sem ser reconhecido) do primeiro artigo científico sobre experimentos de mercado em economia $^{10}$. O que Edward Chamberlin (1899-1967) acreditou ter mostrado foi que a teoria dos mercados competitivos não funciona (apesar

\footnotetext{
${ }^{8}$ Idem. Ibidem., p. 28, 58.

${ }^{9}$ KAGEL, John H. \& ROTH, Alvin E. The Handbook of Experimental Economics. Princeton, N.J.: Princeton University Press, 1995. p. 428, n. 8.

${ }^{10}$ CHAMBERLIN, Edward. An Experimental Imperfect Market. Journal of Political Economy, 61 (April, 1948):
} 95-108. 
dos experimentos realizados em suas aulas terem sido desenhados para preparar o cenário para a necessidade da sua teoria da competição monopolística, os seus experimentos não mostraram que os mercados fracassam em produzir ganhos substanciais a partir das trocas). Minha crítica e modificações do experimento de Chamberlain, incluindo a introdução de recompensas monetárias, e uma mudança de foco no papel das instituições ("organização de mercado") encontram-se em meus ensaios "An Experimental Study of Competitive Market Behavior" [Um Estudo Experimental do Comportamento do Mercado Competitivo] e "Effect of Market Organization on Competitive Equilibrium" [Efeito da Organização de Mercado sobre o Equilíbrio Competitivo], no livro Papers in Experimental Economics [Ensaios de Economia Experimental $]^{11}$. Uma vez que se reconhece o importante papel das instituições (as regras de um mercado em particular), não há nada de estranho ou incomum sobre os resultados de Chamberlin. A economia experimental apoia fortemente a teoria de Mises dos preços de mercado, assim como também a teoria do equilíbrio sob condições estacionárias ou mesmo de mudança dinâmica. A teoria do equilíbrio era vista por Mises, em sua totalidade, como uma "construção imaginária"12. Como de fato ela era, assim como muitas das importantes contribuições de Mises. Tal é a natureza da teoria, que foi totalmente desenvolvida sem a expectativa de que alguém realmente tentaria submetê-la a testes em laboratório. $\mathrm{O}$ que os experimentos de mercado fizeram por mim foi dar vida a esta "construção imaginária". Diante dos meus próprios olhos, pessoas com informação privada (imperfeita), e que, portanto, não tinham previsão dos fins que estavam alcançando, maximizaram os ganhos a partir das trocas e aproximaram os resultados do equilíbrio.

${ }^{11}$ SMITH, Vernon L. Papers in Experimental Economics. New York: Cambridge University Press, 1991. p. 8-55.

${ }^{12}$ MISES. Op. cit., p. 307.
Têm havido agora muitas centenas, provavelmente milhares, de demonstrações experimentais do poder dos mercados - especialmente quando organizadas sob a instituição do "leilão duplo", comum a todos os mercados financeiros e de mercadorias produzir resultados competitivos eficientes, mas também em mercados de posted-offer ${ }^{13} \mathrm{e}$ de compensação de lances fechados e preço único $^{14}$. Esses resultados, que têm sido reproduzidos por numerosos pesquisadores, são robustos com respeito aos participantes utilizados: estudantes de graduação, estudantes de pós-graduação, estudantes secundários e professores, homens e mulheres de negócios; então, em meados dos anos 1980, realizamos um experimento utilizando funcionários administrativos do Departamento de Energia, deixando bem claro que os reguladores poderiam, com a mesma naturalidade, formar um mercado.

$\mathrm{O}$ que aprendemos de tais experimentos é que qualquer grupo de pessoas pode entrar em uma sala, ser incentivado com um ambiente econômico privado bem-definido, ter as regras do leilão duplo oral explicadas a eles pela primeira vez, e podem criar um mercado que geralmente converge para um equilíbrio competitivo, que se torna $100 \%$ eficiente - eles maximizam os ganhos a partir das trocas - dentro de duas ou três repetições de um período de negociação. No entanto, o conhecimento é disperso, com nenhum participante sendo informado da oferta e demanda do mercado, ou mesmo sem entender o que isso significa. Isto demonstra contundentemente o que Adam Smith (1723-1790) chamou de "propensão existente na natureza humana" [...], "a propensão a intercambiar, permutar ou trocar

${ }^{13} \mathrm{O}$ termo posted-offer é mantido no original em inglês no linguajar econômico em português. O conceito é utilizado para descrever os mercados nos quais os vendedores publicam os preços de forma independente no início de cada período de mercado. (N. do T.)

${ }^{14}$ Ver: KAGEL \& ROTH. Op. cit.; DAVIS, Douglas D. \& HOLT, Charles A. Experimental Economics. Princeton: Princeton University Press, 1993; SMITH, V. L. Op. cit. 
uma coisa pela outra"15. Isto também ilustra a asserção de Mises de que:

Todos agem por conta própria; mas as ações de cada um procuram satisfazer tanto as suas próprias necessidades como também as necessidades de outras pessoas. Ao agir, todos servem seus concidadãos ${ }^{16}$.

\section{II - Sobre a Evolução e a Mente Primitiva}

O entendimento de Mises a respeito da evolução está bem de acordo com as interpretações contemporâneas, tal como aquela da psicologia evolutiva ${ }^{17}$.

A mente humana não é uma tábula rasa na qual os eventos externos registram sua própria história. Está equipada com o ferramental necessário para compreender a realidade. O homem adquiriu esse ferramental, isto é, a estrutura lógica de sua mente, ao longo de sua evolução de uma ameba até o estado atual. Mas as ferramentas são anteriores a qualquer experiência [...]. Nenhum ensinamento proporcionado pela etnologia ou pela história contradiz a afirmação segundo a qual a estrutura lógica da mente é uniforme em todos os homens, de todas as raças, idades e países ${ }^{18}$.

Essa é essencialmente a perspectiva corrente da psicologia evolutiva sobre a evolu-

${ }^{15}$ SMITH, Adam. The Wealth of Nations. New York: P. F. Collier, 1909. p. 19. [N. do T.: Todas as citações da obra de Adam Smith em inglês foram substituídas pela versão em português da seguinte edição brasileira: SMITH, Adam. A Riqueza das Nações: Investigação sobre sua Natureza e suas Causas. Apres. Winston Fritsh; Intr. Edwin Cannan; Trad. Luiz João Baraúna. São Paulo: Abril Cultural, 1983. 2v. cit. Vol. I, Livro I, Cap. II, p. 49].

${ }^{16}$ MISES. Op. cit., p. 315.

${ }^{17}$ TOOBY, John \& COSMIDES, Leda. The Psychological Foundations of Culture. In: BARKOW, Jerome H. ; COSMIDES, Leda \& TOOBY John. (Ed.). The Adapted Mind: Evolutionary Psychology and the Generation of Culture. Oxford: Oxford University Press, 1992. p. 19-136.

${ }^{18}$ MISES. Op. cit., p. 62, 65. ção, a mente e, especificamente, a linguagem natural. A afirmação de que adquirimos ferramentas mentais anteriores à experiência é particularmente bem ilustrada no estudo de como adquirimos a linguagem:

Quando os pesquisadores concentram-se em uma regra gramatical (exemplos, em inglês, são os algoritmos que adicionam '-s' a um substantivo regular para formar o seu plural; e que adicionam '-ed' para formar o tempo pretérito de um verbo regular) e contam com qual frequência uma criança obedece a ela e com qual frequência ele ou ela a desrespeita, os resultados são surpreendentes: para qualquer regra que você escolher, crianças de três anos a obedecem na maior parte das vezes ${ }^{19}$.

A interpretação disso é que o cérebro já vem pré-equipado com circuitos prontos para absorver a sintaxe de qualquer linguagem; a inicialização desses circuitos requer somente a exposição a outros indivíduos falantes para a configuração dos interruptores. As exceções (erros) das crianças de três anos na verdade ajudam a demonstrar o princípio: "dois homens estão na porta" 20 , ou "ele construiu a casa" $^{21}$. Verbos e substantivos irregulares precisam ser memorizados e dublados por um processo mental que primeiramente bloqueia o algoritmo de inflexão, e então traz à tona o caso irregular da memória. Muitos casos irregulares raramente são utilizados por adultos, então toma mais tempo desenvolver o processo de bloqueio e substituição, e por isso as crianças de três anos sempre substituem pelo algoritmo para o caso regular. É deste modo que os módulos da linguagem funcionam naturalmente no cérebro. Adultos fazem o mesmo. Com quanta frequência você ouve o pre-

\footnotetext{
${ }^{19}$ PINKER, Steven. The Language Instinct. New York: William Morrow, 1994. p. 271.

${ }^{20}$ No original: "two mans are at the door". O emprego correto da regra gramatical correspondente seria "two men are at the door". (N. do T.)

${ }^{21}$ No original: "he builded the house". O emprego correto da regra gramatical correspondente seria "he built the house". (N. do T.)
} 
térito do verbo strive (strove) $)^{22}$ ou tread (trod) ${ }^{23}$ ? Para muitos, são ocorrências tão raras que eles regularizam como strived ou treaded ${ }^{24}$. De fato, strove e trod tendem a soar pretensioso para muitos ouvidos, sugerindo que o usuário sabe algo importante que você não sabe. Note que a utilização de algoritmos de inflexão é o modo de o cérebro preservar recursos escassos de memória e acesso. Você precisa somente armazenar na memória as raízes e temas básicos, e então invocar algoritmos autonômicos para alavancar as palavras básicas em um vocabulário muito maior. Portanto, "um americano médio egresso do ensino secundário conhece 45.000 palavras - três vezes mais do que William Shakespeare (1564-1616) conseguiu utilizar" [...] "em suas peças e sonetos completos"25.

Contudo, algumas pessoas rejeitam essas interpretações da linguagem, argumentando que nossa habilidade linguística não é uma adaptação, mas sim uma exaptação - um dispositivo que evoluiu para outros propósitos, mas que é aproveitado ou reciclado para uma nova finalidade ${ }^{26}$. Tais pontos de vista, entretanto, parecem-me ser diversivos. A adaptação pode ser complexa, e aproveitar um módulo que, para um biólogo, "aparentemente" foi desenvolvido para outro propósito, é somente um dos muitos caminhos que a adaptação evolutiva pode tomar. É de fato uma pessoa inteligente quem pode dizer para qual propósito evoluiu originalmente um mecanismo biológico particular. Você não precisa acreditar que a linguagem se desenvolveu porque algum proto-humano falou uma palavra que aumentou a sua aptidão, e que o gene para essa palavra então floresceu na população. Mises não tem a pretensão de saber como a evolução criou

\footnotetext{
22 O verbo "to strive" (esforçar-se) tem como forma pretérita "strove". (N. do T.)

${ }^{23} \mathrm{O}$ verbo "to tread" (andar, marchar, pisar) tem como forma pretérita "trod". (N. do T.)

${ }^{24}$ PINKER. Op. cit., p. 273-76.

${ }^{25}$ Idem. Op. cit., p. 150.

26 GOULD, Stephen Jay \& VRBA, Elisabeth S. Exaptation: A Missing Term in the Science of Form. Paleobiology 2 (1981): 4-15.
}

a capacidade mental humana, mas para ele é igualmente natural conceber a mente como um fenômeno que evoluiu, da mesma forma como é acreditar que braços e pernas foram criados pelo processo evolutivo.

Stephen Jay Gould (1941-2002) e Richard Lewontin têm acusado muitos biólogos evolucionistas de conferirem muito crédito à seleção natural ${ }^{27}$. Os descendentes intelectuais de Mises deleitar-se-ão na avaliação do psicólogo e linguista Steven Pinker a respeito do influente artigo de Gould e Lewontin: "Um de seus objetivos era minar as teorias do comportamento humano que eles vislumbravam que pudessem ter implicações políticas de direita"28. A Harvard University de Gould é, obviamente, um exemplo proeminente da afirmação de algum gracejador de que os únicos marxistas que restaram no mundo estão lecionando nas universidades britânicas e norte-americanas. Parece que os esquerdistas, que promovem a perfectibilidade dos seres humanos por intermédio do controle social (i.e., do governo), temem as implicações de atribuir muita influência à natureza, enquanto os direitistas (ao menos a parcela dos que defendem fortemente o governo limitado) temem as implicações estatistas da maleabilidade humana. Este é o debate entre conhecimentos inatos e adquiridos, o qual está repleto de vieses políticos ocultos. Mises decide-se pelo lado da natureza, do conhecimento inato, ao argumentar que a mente possui ferramentas que não são parte da experiência. Mas a mente possui essas ferramentas porque elas foram adaptáveis, porque elas floresceram em ambientes que não bloquearam sua expressão. Portanto, uma visão contemporânea importante é a da coevolução da natureza e da cultura - a cultura influencia o que sobrevive e floresce, enquanto a natureza influencia o que é mais ou menos maleável.

\footnotetext{
${ }^{27}$ GOULD, Stephen Jay \& LEWONTIN, Richard. The Spandrels of San Marco and the Panglossian Paradigm: A Critique of the Adaptionist Programme. Proceedings of the Royal Society B, 205 (1979): 581-98.
}

${ }^{28}$ PINKER. Op. cit., p. 359. 


\section{III - Sobre Ações Conscientes versus INCONSCIENTES}

Neste ponto, Mises foi ultrapassado por desenvolvimentos recentes na neurociência, pois declara, o "comportamento consciente ou propositado contrasta acentuadamente com comportamento inconsciente, isto é, os reflexos e as respostas involuntárias das células e nervos do corpo aos estímulos" ${ }^{\prime 29}$. Ele deseja afirmar que a ação humana é conscientemente proposital. Mas essa não é uma condição necessária para o seu sistema. Os mercados estão agindo independentemente do motivo principal da ação humana envolver escolhas deliberativas autoconscientes.

Ele minimiza amplamente a operação de processos mentais inconscientes. A maior parte do que nós sabemos não nos lembramos de termos aprendido, assim como o processo de aprendizagem também não é acessível à nossa experiência consciente - a mente. Uma criança em desenvolvimento normal aprende uma linguagem natural sintaticamente correta por volta dos quatro anos de idade, sem ter sido ensinada. Como observado por Pinker, "as crianças merecem a maior parte do crédito pela linguagem que adquirem. De fato, podemos mostrar que elas sabem coisas que não poderiam ter-lhes sido ensinadas ${ }^{\prime \prime 30}$. Mesmo importantes problemas de decisão que enfrentamos são processados pelo cérebro abaixo da acessibilidade da consciência. Isto é perceptível quando você está tendo dificuldades para tomar uma decisão, ou está tentando resolver um problema, então vai dormir, e acorda tendo feito um progresso significativo ou mesmo tendo encontrado a solução. Como observa o neurocientista Michael Gazzaniga, com sua prosa caracteristicamente clara:

No momento em que pensamos que conhecemos alguma coisa - (ou seja, que) ela é parte de nossa experiência consciente - o cérebro já tinha feito seu trabalho. Trata-se de algo passado para o cérebro, mas recente

\footnotetext{
${ }^{29}$ MISES. Op. cit., p. 35.

${ }^{30}$ PINKER. Op. cit., p. 40.
}

para "nós" (a mente consciente). Os sistemas embutidos no cérebro fazem seu trabalho automaticamente e em grande parte fora da nossa percepção consciente. $O$ cérebro termina o seu trabalho meio segundo antes que a informação que ele processa alcance a nossa consciência[...]. Nós (ou seja, nossas mentes) não possuímos indícios a respeito de como tudo isto funciona e é realizado. Nós não planejamos ou articulamos essas ações. Nós simplesmente observamos o produto [...]. O cérebro começa a encobrir este aspecto de "negócio fechado" do seu funcionamento criando em nós a ilusão de que os eventos que estamos vivenciando estão acontecendo em tempo real - [e] não antes da nossa experiência consciente de decidir fazer alguma coisa ${ }^{31}$.

De fato, um dos enigmas da neurociência é o de por que o cérebro engana a mente fazendo-a acreditar que está no comando da atividade mental. Mas nada disso afeta a importância do argumento de Mises. Mercados são uma das maneiras que o cérebro social possui para estender sua capacidade de processamento de informações para outros cérebros, e para alavancar a criação de riqueza para além de qualquer coisa que possa ser compreendida pela mente. Assim como a maior parte do que o cérebro faz é inacessível para a mente, também há um fracasso generalizado das pessoas para entender os mercados como sistemas auto-organizáveis, coordenados por preços para a obtenção cooperativa de ganhos a partir das trocas, sem que exista alguém no comando. $\mathrm{O}$ funcionamento da economia é tão inacessível à consciência de seus agentes, inclusive às pessoas de negócios, quanto o é a consciência de um agente a respeito do funcionamento de seu próprio cérebro. $\mathrm{O}$ funcionamento da economia não é o produto, nem pode ser o produto, da razão consciente, a qual deve reconhecer suas próprias limitações e enfrentar, nas palavras de Hayek, "as implicações do surpreendente

\footnotetext{
${ }^{31}$ GAZZANIGA, M. The Mind's Past. Berkeley: University of California Press, 1998. p. 63-64.
} 
fato, revelado pela economia e a biologia, de que a ordem gerada sem uma intenção pode ultrapassar de longe os planos conscientemente idealizados pelos homens" ${ }^{\prime \prime 32}$.

\section{IV - Sobre a Especialização dos Circuitos Cerebrais para Discer- nir Custos de Oportunidade, e o Nexo RAZÃo-Emoções}

Um tema persistente em Mises é o de que a escolha é baseada nas comparações de preferências e julgamentos de uma pessoa pensante e racional a respeito do que significa mais ou do que significa menos: "Qualquer ação é uma tentativa para substituir uma situação menos satisfatória por outra mais satisfatória" [...] "O custo é igual ao valor atribuído à satisfação de que nos privamos, a fim de obter o objetivo pretendido" ${ }^{\prime \prime 3}$.

Mas somente o homem tem a faculdade de transformar estímulos sensoriais em observações e experiência. E somente o homem pode ordenar suas várias observações e experiências num sistema coerente. O pensamento precede a ação ${ }^{34}$.

Desejo chamar a atenção para o fato de que uma linha de pesquisa humana e animal que remonta ao mesmo ano de publicação de Ação Humana demonstra a base para comparações de valores que são renunciados no funcionamento natural do cérebro animal. David J. Zeaman relatou experimentos nos quais ratos foram treinados para correr em direção a uma grande recompensa. Então, esses ratos

${ }^{32}$ HAYEK, F. A. The Fatal Conceit: The Errors of Socialism. Chicago: University of Chicago Press, 1988. p. 8. [N. do T.: Todas as citações da obra de Hayek em inglês foram substituídas pela versão em português da seguinte edição brasileira: HAYEK, F. A. Arrogância Fatal: Os Erros do Socialismo. Trad. Ana Maria Capovilla e Candido Mendes Prunes. Porto Alegre: Editora Ortiz / Instituto de Estudos Empresariais, 1995. cit. p. 23].

${ }^{33}$ MISES. Op. cit., p. 130.

${ }^{34}$ Idem. Ibidem., p. 221. foram deslocados e postos diante de uma recompensa pequena, e os ratos responderam correndo mais devagar do que teriam corrido se somente tivessem sido apresentados à pequena recompensa ${ }^{35}$. Um segundo grupo de ratos começou com uma recompensa pequena e depois foram transferidos para uma recompensa grande, e esses ratos correram imediatamente mais rápido do que se somente a recompensa grande tivesse sido aplicada. Esse experimento inicial era consistente com a hipótese de que a motivação era baseada na recompensa relativa - o custo de oportunidade - e não em uma escala absoluta de valores gerada pelo cérebro. Mas essa interpretação não foi apreciada na época. Desde então, medições diretas da atividade neuronal no cérebro têm revelado a importância das comparações de valor relativas no modo como os cérebros dos mamíferos realmente funcionam. Assim, tanto cérebros de macacos quanto de ratos responderam a comparações diferenciais de recompensas. Estudos neurofisiológicos de macacos e ratos mostram que os neurônios das seis camadas do córtex orbitofrontal (acima dos olhos) processam eventos motivadores, discriminam entre estímulos condicionais apetitivos e adversos e estão ativos durante a expectativa dos resultados ${ }^{36}$.

Atualmente está provado que a atividade dos neurônios orbitofrontais em macacos permite-lhes discriminar entre recompensas relativas que estão diretamente relacionadas às preferências relativas dos animais por recompensas tais como passas, maçã e cereal (em ordem decrescente de preferências). Logo, a atividade neuronal é maior para passas do que para maçã quando o sujeito está vendo passas e maçã, e, similarmente, quando a comparação é entre maçã e cereal. A atividade associada com a maçã, no entanto, é muito maior quan-

${ }^{35}$ ZEAMAN, David J. Response Latency as a Function of the Amount of Reinforcement. Experimental Psychology, 39 (1949): 466-83.

36 TREMBLAY, Léon \& SCHULTZ, Wolfram. Relative Reward Preference in Primate Orbitofrontal Cortex. Nature 398 (22 April 1999): 704-08. 
do comparada com o cereal do que quando é comparada com as passas. Isso é o contrário do que seria esperado observar se as três recompensas fossem codificadas em uma escala fixa de propriedades físicas e não em uma escala relativa ${ }^{37}$.

Dado que as tecnologias utilizadas em estudos animais são muito invasivas para a aplicação em seres humanos, qual é o significado, para os humanos, dessas considerações a respeito de como o cérebro animal funciona? A resposta é que outra pesquisa mostrou que o córtex orbitofrontal em humanos e em macacos realiza muitas das mesmas funções genéricas. Isso está indicado por intermédio de estudos de humanos e macacos que apresentam danos neste tecido: ambas as espécies exibem expressões alteradas de recompensa e preferências, além de prejuízo do comportamento de tomada de decisões, motivacional e emocional, o que leva a anormalidades significativas no comportamento social. Como observado por António Damásio, sintetizando esta literatura:

Apesar das acentuadas diferenças neurobiológicas entre certos macacos e o chimpanzé, e entre o chimpanzé e o humano, existe uma essência compartilhada para o defeito causado pelo dano pré-frontal: o comportamento pessoal e social é severamente comprometido $^{38}$.

As pessoas gostam de acreditar que a boa tomada de decisões é uma consequência do uso da razão, e que qualquer influência que as emoções possam desempenhar é antitética a boas decisões. O que não é apreciado por Ludwig von Mises, assim como por outros que de forma similar confiam na primazia da razão na teoria da escolha é o papel construtivo que

\footnotetext{
${ }^{37}$ Idem. Ibidem., p. 706, fig. 4.

${ }^{38}$ DAMASIO, Antonio. Descartes' Error: Emotion, Reason and the Human Brain. New York: Avon Books, 1994. p. 75. [N. do T.: O livro do neurologista português foi publicado em língua portuguesa na seguinte edição brasileira: DAMÁSIO R., António. O Erro de Descartes: Emoção, Razão e o Cérebro Humano. Trad. Dora Vicente e Georgina Segurado. São Paulo: Companhia das Letras, 1996].
}

as emoções desempenham na ação humana. Por exemplo, Antoine Bechara, Hanna Damásio, Daniel Tranel e António Damásio estudaram o comportamento de pacientes com danos no lobo frontal em experiências de tomada de decisões em condições de incerteza, e compararam seus comportamentos com indivíduos normais ${ }^{39}$. Eles mostram que os indivíduos normais, à medida que aprendem sobre o ambiente experimental, entram em uma transição crítica, na qual eles mudam seus padrões decisórios. Contudo, antes da mudança na decisão, testes de condutividade da pele registram uma resposta emocional, ao passo que somente após a mudança da decisão eles estão aptos a articular verbalmente por que fizeram essa mudança. Portanto, o cérebro emocional age antes da mudança na decisão, enquanto a razão, na forma de racionalização verbal, ocorre após a decisão. Os pacientes com lesões cerebrais, contudo, fracassaram em mostrar a resposta emocional, falharam em mudar suas tomadas

${ }^{39}$ BECHARA, Antoine ; DAMASIO, Hanna ; TRANEL Daniel \& DAMASIO, Antonio. Deciding Advantageously before Knowing the Advantageous Strategy. Science, 275, (28 February 1997): 1293-94. A tarefa dos indivíduos é aumentar seu estoque de dinheiro virando cartas de qualquer um ou de todos dentre quatro baralhos. As cartas nos baralhos A e B rendem $\$ 100$, e de $C$ e $D$ rendem $\$ 50$. Nos baralhos A e B, entretanto, aparece ocasionalmente uma carta com uma perda grande e imprevisível. As penalidades continuam sem seguir um padrão, e os sujeitos não sabem quando a tarefa terminará. Todos os sujeitos têm eletrodos conectados à pele para medir a resposta galvânica da pele (GSR). A resposta emocional a eventos faz com que os humanos transpirem mais, e isso é registrado como uma maior condutividade da pele, o que é medido por uma leitura mais alta no galvanômetro. O primeiro resultado interessante do experimento foi que houve uma resposta emocional detectada nas leituras GRS dos indivíduos normais antes da decisão de mudar dos baralhos A e B para os baralhos C e D. Somente então, após a mudança na tomada de decisão, os indivíduos puderam articular verbalmente por que eles estavam mudando. A segunda observação importante é que os pacientes com lesões no lobo frontal não mudavam para os baralhos $\mathrm{C}$ e $\mathrm{D}$, não houve mudança associada nas leituras de GSR, e eles tenderam a oferecer desculpas verbais a respeito de seus maus desempenhos, algumas indicando que os baralhos A e B poderiam ficar melhores. 
de decisão, e apresentaram desculpas verbais para o seu fraco desempenho. De modo interessante, um problema genérico com os pacientes em suas histórias de vida é a tendência para perderem seus empregos, irem à falência, e terem dificuldades em tomar decisões de longo prazo satisfatórias. Esses quatro pesquisadores acreditam que há sugestões inconscientes do cérebro emocional (às vezes chamado de sistema límbico) que guiam ou influenciam a formação de estratégias cognitivas, e que este circuito é efetuado por lesões no lobo frontal. Consequentemente, as emoções, longe de serem inimigas da decisão racional, podem ser essenciais a ela, ao passo que o cérebro consciente dotado de razão é o último a saber.

\section{V - Sobre a Sociedade Humana e A Cooperação}

De acordo com Mises, todas as relações sociais resultam da divisão do trabalho, a qual é possibilitada pela economia de mercado:

No quadro da cooperação social podem emergir, entre os membros da sociedade, sentimentos de simpatia e amizade e uma sensação de comunidade. Esses sentimentos são a fonte, para o homem, das mais agradáveis e sublimes experiências. São o mais precioso adorno da vida [...]. Entretanto, esses sentimentos não são [...]. Os que engendraram as relações sociais. São fruto da cooperação social e só vicejam no seu quadro [...]. Os fatos fundamentais que fizeram existir a cooperação, a sociedade e a civilização, e que transformaram o animal homem num ser humano, é o fato de que o trabalho efetuado valendo-se da divisão do trabalho é mais produtivo que o trabalho solitário, e o fato de que a razão humana é capaz de perceber esta verdade $\mathrm{e}^{40}$.

Quero colocar uma interpretação totalmente distinta sobre essas questões, sem, creio eu, negar, ou desvalorizar, a principal importância da mensagem de Mises. Minha versão,

${ }^{40}$ MISES. Op. cit., p. 183. baseada em estudos arqueológicos, etnográficos e experimentais, oferece uma perspectiva diferente para as origens psicológico-sociais das trocas, dos direitos de propriedade e do dinheiro. Dado que já desenvolvi este tema em outros lugares ${ }^{41}$, aproveitarei esta oportunidade para atualizá-lo e reformulá-lo no contexto de honrar as contribuições duradouras de Ludwig von Mises.

Talvez perdendo apenas para a linguagem como um universal humano, as pessoas continuamente, e em grande medida inconscientemente, envolvem-se em reciprocidade com amigos, associados e mesmo estranhos se o contexto não for percebido como hostil. Você convida conhecidos para jantar, e subsequentemente eles convidam você. Você dá seus ingressos para o teatro para uma amiga quando você está fora da cidade, e subsequentemente ela te dá ingressos que ela não pode utilizar para um concerto. Amigos trocam favores, emprestam propriedades, e fornecem serviços um para o outro de forma autônoma, sem manter registros rigorosos. Daí a frase usual, "eu te devo uma". Sociedades de caçadores e coletores estudadas nos últimos cem anos estão repletas de sistemas sociais de trocas que têm implicações econômicas de longo alcance. Apesar de algumas apresentarem formas de moeda-mercadoria, muitas não têm nenhuma e confiam inteiramente nas trocas sociais por meio da reciprocidade para captar ganhos a partir das trocas em um mundo sem dinheiro ou refrigeração. As formas das instituições variam amplamente, mas sua funcionalidade é a mesma. Existe uma acentuada divisão de trabalho através das gerações e entre os sexos: em geral mulheres, crianças e idosos coletam e processam alimentos vegetais; homens e meninos com mais de 18 anos caçam; homens mais velhos aconselham nas caçadas e fazem ferramentas; e as avós auxiliam nos nascimentos e na criação das crianças como parte de uma adaptação biológica caracteristicamente humana - a menopausa, que leva a uma prolongada

${ }^{41}$ SMITH, Vernon L. The Two Faces of Adam Smith. Southern Economic Journal, 65 (July 1998): 1-19. 
vida pós-reprodutiva familiar e de serviços à comunidade.

Esse "instinto" para a reciprocidade tem vindo à tona fortemente e de forma inesperada em diversos experimentos laboratoriais de forma extensiva ${ }^{42}$. Conforme indicado acima, a pesquisa experimental de mercado corrobora fortemente o tema de Smith-Hayek-Mises da cooperação por intermédio das instituições do mercado, nas quais os direitos de propriedade aproveitam o interesse próprio para criar riqueza. Mas a metade ou mais dos mesmos sujeitos que inconscientemente maximizam os ganhos a partir das trocas em interações anônimas por um conjunto de regras de mercado também escolhem abrir mão da ação em interesse próprio para obter resultados cooperativos pela confiança e da confiabilidade em interações anônimas em jogos simples de informação completa.

Por exemplo, em um dos jogos da confiança, doze sujeitos chegam ao laboratório para "ganhar dinheiro em um experimento econômico". Assim que os indivíduos chegavam, eles recebiam $\$ 5$ por chegarem pontualmente e eram designados a um terminal de computador em uma sala contendo quarenta máquinas separadas por divisórias. Depois que todos os sujeitos chegavam eles conectavam, e cada um deles era aleatória e anonimamente emparelhado com outro sujeito na sala, e a ordem de ser o primeiro ou segundo a fazer seu movimento era designada aleatoriamente.

$\mathrm{O}$ jogo é jogado uma vez. O primeiro a mover podia escolher dividir \$20 igualmente, \$10 para ele e \$10 para o segundo jogador. Alternativamente, ele poderia passar a vez para o jogador 2, o que dobrava o bolo original para $\$ 40$. O jogador 2 tinha duas opções: ficar com os $\$ 40$, sem deixar nada para o jogador 1 , ou

\footnotetext{
${ }^{42}$ FEHR, Ernst ; GÄCHTER, Simon \& KIRCHSTEIGER, Georg. Reciprocity as a Contract Enforcement Device: Experimental Evidence. Econometrica, 65 (1996): 833-60; McCABE, Kevin A.; RASSENTI, Stephen J. ; \& SMITH, Vernon L. Game Theory and Reciprocity in Some Extensive Form Experimental Games. Proceedings National Academy of Science, 93 (1996), 13421-28.
}

ficar com \$25, deixando \$15 para o jogador 1 . Qualquer que fosse a escolha, no final cada indivíduo recebia o pagamento em privado, e deixava o experimento. $\mathrm{O}$ experimento todo durava em torno de 15 minutos. Nenhum sujeito sabia com quem ele estava emparelhado. Reconhece-se amplamente que este protocolo de jogo único com emparelhamento anônimo define as condições mais favoráveis para jogadas não cooperativas de parte de cada jogador. A teoria dos jogos assume que, na ausência de jogadas interadas, ou de qualquer história ou de interações futuras entre os jogadores, cada jogador escolherá estratégias dominantes, e cada um assumirá que o outro fará a mesma coisa. Consequentemente, o equilíbrio (de subjogo perfeito) do jogo é ficar com \$10, deixando $\$ 10$ para o jogador 2. De outra maneira, se o primeiro jogador escolher passar a jogada para o segundo jogador, ele escolherá ficar com o total dos $\$ 40$.

De forma alternativa, suponha que o jogador 1 seja uma pessoa cuja política nas interações sociais com outros seja geralmente iniciar uma troca amigável. Neste contexto, passar a jogada para o jogador 2 destina-se a servir como uma oferta para que ele coopere. O jogador 1 arrisca uma oportunidade de perda de $\$ 10$ por uma oportunidade de ganho de $\$ 5$. Isto pode ser interpretado como uma sinalização para o jogador 2 dando a entender que: “eu não estou desistindo da certeza de $\$ 10$ por esperar que você me deixe com $\$ 0$; estou oferecendo a você um retorno de $250 \%$, para que eu possa receber um retorno de $150 \%$ a partir da troca. Estou confiando que você seja digno de confiança". Se o jogador 2 tiver inclinação semelhante, nós temos uma troca, produzindo ganhos a partir da troca, na qual o jogador 1 recebe $\$ 15$ e o jogador 2 recebe $\$ 25$.

A tabela abaixo apresenta os resultados para uma amostra de 24 pares de estudantes de graduação e uma amostra de 28 pares de estudantes avançados de pós-graduação ${ }^{43}$. A

43 Dados disponíveis em: McCABE, Kevin A. \& SMITH, Vernon L. A Comparison of Naive and Sophisticated Subject Behavior with Game Theoretic 
lição é que a metade da amostra dos estudantes universitários, inclusive estudantes avançados de pós-graduação de todo os Estados Unidos e a Europa, com formação em economia e em teoria dos jogos, é propensa a confiar, enquanto algo entre 64 a $75 \%$ das suas contrapartes correspondentes são dignos de confiança. Por que uma proporção tão grande desses sujeitos interagindo anonimamente abdica das ações não cooperativas em interesse próprio previstas pela teoria econômica e pela teoria dos jogos? Acreditamos que a razão é simples: a maior parte das pessoas nas sociedades relativamente estáveis acredita que compensa, no longo prazo, mostrar uma face cooperativa e afável para seus semelhantes. Esta postura habitual é tão forte que ela sobrevive até em um jogo experimental de interação anônima desconhecida, jogado uma vez; a maior parte das contrapartes emparelhadas compreendem a mensagem, e agem com reciprocidade para a sua vantagem mútua. Nossos dados mostram que os jogadores 1 que cooperam, arriscando ser traídos, em média conseguem mais dinheiro do que aqueles que não cooperam.

Porcentagem de pares obtendo o resultado condicional indicado por tratamento dos participantes utilizados

\begin{tabular}{|c|c|c|}
\hline Resultado & $\begin{array}{c}\text { Estudantes de } \\
\text { Graduação }\end{array}$ & $\begin{array}{c}\text { Estudantes Avançados } \\
\text { de Pós-Graduação }\end{array}$ \\
\hline$(10,10)$ & $12(50 \%)$ & $14(50 \%)$ \\
\hline$(15,25)^{\mathrm{a}}$ & $9(75 \%)$ & $9(64,3 \%)$ \\
\hline$(0,40)^{\mathrm{a}}$ & $3(25 \%)$ & $5(35,7 \%)$ \\
\hline
\end{tabular}

(a) Número de pares obtendo este resultado condicional ao alcançar o segundo estágio do jogo (o jogador 1 passa). Logo, com os estudantes de graduação, 12 dos 24 jogadores 1 jogaram "abaixo", dos quais 9 jogadores 2 moveram "direita" e 3 moveram "abaixo".

Predictions. Proceedings of National Academy of Science, 97, 7 (March 2000): 3777-81. Ver, também: GUNNTHORSDOTTIR, Anna ; McCABE, Kevin A. ; \& $\mathrm{SMITH}$, Vernon L. Using the Machiavellian Instrument to Predict Trustworthiness in a Bargaining Game. Journal of Economic Psychology, 23 (2002): 49-66.
Quero sugerir que esse tipo de comportamento em forma de desenvolvimento tem sido caraterístico de nossos ancestrais, provavelmente ao longo dos últimos dois milhões de anos. De fato, concordaria com Mises em que foi por intermédio das trocas que nós chegamos ao ponto em que estamos hoje, exceto que, pela maior parte da nossa história, as trocas ocorreram por meio da reciprocidade na família, na família estendida, e na tribo. Foi isso o que lançou as bases para a especialização inicial, muito antes do surgimento dos mercados. Consequentemente, quando alguém inventou a permuta, e mais tarde o que seria chamado de "dinheiro" (sem dúvida, assim como a linguagem, ele foi "inventado" vezes sem conta), os humanos já possuíam uma vasta experiência de trocas sociais. O que o dinheiro permitiu foi libertar a mente da contabilidade da boa vontade - a necessidade de checar periodicamente para ver se a sua conta de boa vontade com um amigo não estava muito desequilibrada. Este novo elemento pode ter tornado possível a troca de longa distância, a qual culminou hoje nos mercados mundiais e no começo da era do comércio eletrônico ${ }^{44}$. O modelo do indivíduo apresentado acima - comportar-se não cooperativamente em mercados impessoais e maximizar os ganhos a partir das trocas, mas cooperativamente nas trocas pessoais para também maximizar os ganhos a partir das trocas - permite-nos entender por que as pessoas continuam desejando intervir nos mercados para "melhorar" a situação. A sua experiência nos intercâmbios sociais pessoais é que fazer o bem (sendo propenso a confiar e digno de confiança) leva a atingir o bem (ganhos visíveis a partir das trocas sociais). Nas trocas impessoais por meio dos mercados, os ganhos a partir das trocas não são parte de sua experiência. Conforme observado por Adam Smith, "essa divisão do trabalho, da qual derivam tantas vantagens, não é, em sua origem, o efeito de uma sabedoria humana qualquer, que preveria

${ }^{44}$ NORTH, Douglass C. Institutions, Institutional Change, and Economic Performance. New York: Cambridge University Press, 1991. 
e visaria esta riqueza geral à qual dá ocasião"45. As trocas impessoais por intermédio dos mercados tendem a ser percebidas como um jogo de soma zero, uma percepção que de forma alguma diminui a capacidade dos mercados de realizarem o trabalho articulado por Adam Smith e Ludwig von Mises. Os programas intervencionistas, sugiro, resultam de pessoas aplicando de forma inapropriada suas intuições e experiências advindas das trocas sociais pessoais aos mercados, e concluindo que deveria ser possível intervir e tornar as coisas melhores. As pessoas usam sua intuição, e não sua razão (como era esperado por Mises) quando pensam sobre os mercados, e elas se equivocam.

\section{Conclusão}

Duas características, exclusivas à linhagem dos hominídeos, são provavelmente centrais à emergência da especialização (a ordem estendida da cooperação), como um universal humano que permitiu aos nossos ancestrais proto-humanos o domínio "sobre os peixes do mar, as aves do céu, os animais domésticos, todas as feras e todos os répteis que rastejam sobre a ter-

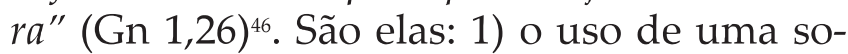
fisticada linguagem natural; e 2) a reciprocidade, ou "a propensão a intercambiar, permutar ou trocar uma coisa pela outra"47. É difícil imaginar que essas duas características puderam evoluir de forma independente. Elas formam, quase certamente, parte de um nexo coevolutivo cultural e biológico que remonta a mais de dois milhões de anos. O instinto para realizar trocas explica a sobrevivência de sistemas de comércio na China, na antiga União Soviética e em outros lugares sob repressão estatal e tentativa de repressão social.

Ludwig von Mises e F. A. Hayek articularam e enriqueceram amplamente os princí-

\footnotetext{
${ }^{45}$ SMITH, A. Op. cit., Vol. I, Livro I, Cap. II, p. 49.

${ }^{46}$ A versão em português dessa passagem do Gênesis foi retirada da seguinte edição brasileira: Bíblia de Jerusalém. São Paulo: Paulus, 1995. (N. do T.)

${ }^{47}$ SMITH, A. Op. cit., Vol. I, Livro I, Cap. II, p. 49.
}

pios de Adam Smith em um momento crucial do século XX, quando o seu pensamento era amplamente rejeitado como sendo anacrônico, inviável e ideológico. Eles defenderam a liberdade quando ela não tinha apoio popular; eles falaram com perspicácia e sabedoria. Mas falaram a partir de perspectivas independentes, e às vezes contraditórias. Para Mises, "a razão" [...] "é o marco que" [...] [originou] "todas as realizações que consideramos especificamente humanas" 48 . No entanto, para Hayek, a presunção fatal é "a ideia de que a capacidade de adquirir habilidades deriva da razão. Pois se trata do contrário: nossa razão é tanto o resultado de um processo de solução evolucionária quanto nossa moral", mas ela decorre de um desenvolvimento separado - "nunca poderíamos pressupor, que nossa razão se encontra na mais alta posição crítica e que só são válidas as normas morais que a razão endossa"49.

Para compreender nossa civilização é preciso perceber que esta ordem não foi fruto do desígnio ou da intenção humana, mas nasceu espontaneamente; nasceu de certos costumes tradicionais e em grande parte morais, muitos dos quais desagradam aos homens, cuja importância estes em geral não entendem, e cuja validade não podem provar, e que, não obstante, se difundiram de modo relativamente rápido, graças a uma seleção evolucionária - o crescimento comparativo da população e da riqueza, dos grupos que por acaso os seguiram ${ }^{50}$.

Apesar de Hayek, no meu entender, ser o principal pensador econômico do século $X X$, aquele que viu quais devem ser as razões principais da ordem estendida, Mises foi o perito da escolha, e ninguém foi melhor do que ele para articular a primazia do indivíduo e a necessidade de definir e cuidar dos direitos individuais. A economia experimental, criada na década de 1950 desde o Ação Humana, é uma boa oportunidade para os austríacos, no

\footnotetext{
${ }^{48}$ MISES. Op. cit., p. 123.

${ }^{49}$ HAYEK. Op. cit., p. 40.

${ }^{50}$ Idem. Ibidem., p. 21.
} 
que nos permite demonstrar que a ordem espontânea, operando por intermédio das instituições dos direitos de propriedade, exibe as características desejáveis que os austríacos reivindicaram. Este poder de demonstração é, para mim, muito mais atraente do que o apelo à razão, especialmente por Mises. Afinal de contas, alega-se também que a razão está ao lado da intervenção estatal, forma da razão tem um modo de comandar as mentes das pessoas devido à sua correspondência superficial com a sua experiência, mesmo quando os sistemas por ela criados desmoronam ao redor, e fazem-nas desesperar de que tudo ficaria bem, não fossem os humanos tão gananciosos. cos 